University of South Florida

DIGITAL COMMONS

Digital Commons @ University of

@ UNIVERSITY OF SOUTH FLORIDA

South Florida

School of Geosciences Faculty and Staff

Publications

School of Geosciences

$11-1993$

\title{
Continuous Monitoring of High-Temperature Fumaroles on an Active Lava Dome, Volcán Colima, Mexico: Evidence of Mass Flow Variation in Response to Atmospheric Forcing
}

\author{
Charles B. Connor \\ Florida International University, cbconnor@usf.edu \\ Bradford M. Clement \\ Florida International University \\ XiaoDan Song \\ Florida International University \\ Sammantha B. Lane \\ Florida International University \\ Jennifer West-Thomas \\ Florida International University
}

Follow this and additional works at: https://digitalcommons.usf.edu/geo_facpub

Part of the Earth Sciences Commons

\begin{abstract}
Scholar Commons Citation
Connor, Charles B.; Clement, Bradford M.; Song, XiaoDan; Lane, Sammantha B.; and West-Thomas, Jennifer, "Continuous Monitoring of High-Temperature Fumaroles on an Active Lava Dome, Volcán Colima, Mexico: Evidence of Mass Flow Variation in Response to Atmospheric Forcing" (1993). School of Geosciences Faculty and Staff Publications. 1659.

https://digitalcommons.usf.edu/geo_facpub/1659
\end{abstract}

This Article is brought to you for free and open access by the School of Geosciences at Digital Commons @ University of South Florida. It has been accepted for inclusion in School of Geosciences Faculty and Staff Publications by an authorized administrator of Digital Commons @ University of South Florida. For more information, please contact digitalcommons@usf.edu. 


\title{
Continuous Monitoring of High-Temperature Fumaroles on an Active Lava Dome, Volcán Colima, Mexico: Evidence of Mass Flow Variation in Response to Atmospheric Forcing
}

\author{
Charles B. ConNor, ${ }^{1}$ Bradford M. Clement, Xiaodan Song, Sammantha B. Lane, and JenNifer West-Thomas
}

Department of Geology, Florida International University, Miami

\begin{abstract}
Rapid, multichannel monitoring of fumaroles on Volcál Colima, Mexico, provides new insight into the timescales and magnitudes of fumarole temperature variation. Temperatures in five fumaroles, all located along a single fracture cutting the summil lava dome of the volcano, were monilored at 20-min intervals between May 1991 and May 1992. Measurements were made using a programmable data logger deployed near the fumarole field, and data were radiotelemetered to a nearby volcano observatory at regular intervals. Mean fumarole temperatures varied between $350^{\circ} \mathrm{C}$ and $550^{\circ} \mathrm{C}$. Statistical analysis of these time series shows that significant diumal variation occurs in each fumarole. Magnitudes of these daily fluctuations are generally between $25^{\circ} \mathrm{C}$ and $50^{\circ} \mathrm{C}$, although larger-amplitude variations occur, especially in cooler fumaroles. Simultaneous monitoring of atmospheric pressure at the fumaroles indicales that these variations in temperature are inversely correlated with barometric pressure. These observations indicate that fumarole temperatures respond to atmospheric forcing. A numerical model developed to explore the dependence of fumarole temperature on mass flow demonstrates that many aspects of observed temperature variation are accounted for by mass flow variation, resulting from small changes in barometric pressure. The relationship between mass flow and fumarole temperature is nonlinear: the response of fumarole temperalures to a given change in mass flow is greatest in fumaroles with low mass flow (and cool temperatures). The nature of this dependence is little affected by fumarole geometry for the cases considered. Continuous measurement of fumarole temperatures may be an effective means of monitoring local mass flow on volcanoes. At Volcán Colima, average temperatures changed by less than $100^{\circ} \mathrm{C}$ during the 1-year sampling period. During and immediately following effusive activity, changes in degassing were abrupt and inconsistent along the length of the fracture. Following this period, temperatures decreased gradually, and there was a higher degree of correlation between fumaroles. The method described here represents a substantial improvement over traditional fumarole-monitoring techniques because subtle variation can be quickly identified using standard statistical techniques, and the method provides regular information about thermal activity on a volcano, minimizing the hazards normally associated with the collection of these data on a regular basis.
\end{abstract}

\section{INTRODUCTION}

Fumaroles are among the most obvious manifestations of volcanic activity. Fumarole temperatures often rise prior to volcanic eruptions [e.g., Zettwood and Tazieff, 1973; Barquero, 1988; Tedesco et al., 1991] and therefore may provide information critical to the evaluation of the state of activity of the volcano. Often, increases in fumarole temperature are rapid. For instance, fumarole temperatures in the crater of Volcán Poás rose by over $700^{\circ} \mathrm{C}$ in 1 month in 1980, precursory to phreatic eruptions which began several weeks later [Barquero, 1983]. Similar rapid changes have been observed in ground temperature on Mount Etna [McClelland et al., 1989] and in hot spring temperatures at Usu volcano [Abiko, 1984, 1988] prior to volcanic enuptions. Conversely, decreases in fumarole temperatures over periods of months or years are often the most apparent sign of waning volcanic activity [e.g., Allen and Zies, 1923; Stoiber et al., 1975; Barquero, 1988; Keith, 1991].

Fumarole temperature data, however, have been of limited use in volcano monitoring and in the mitigation of volcanic hazards for two reasons. First, fumaroles, the loci of convective heat loss at the volcano, are usually local manifestations. It is difficult to relate temperatures at these fumaroles directly to the movement of magma or related changes in the thermal structure of the volcano. This dif-

${ }^{1}$ Now at Center for Nuclear Waste Regulatory Analyses, Southwest Research Institute, San Antonio, Texas.

Copyright 1993 by the American Geophysical Union.

Paper number 93JB02169.

0148-0227/93/93JB-02169\$05.00 ficulty is compounded by the numerous factors that can inlluence fumarole temperature. These factors include variation in mass flow through the fumarole conduit; conduit geometry; mixing with meteoric water vapor or air; variation in the temperature of the gas at its source due to, for example, cooling and crystallization; and variation in the depth to the magma. Second, fumarole temperatures have, in the past, been monitored at infrequent intervals because of the hazards and logistical difficulties inherent in the collection of these data. Particularly in times of volcanic crisis, fumarole temperature data usually cannot be collected using traditional sampling methods. Sampling at these times, however, is most relevant to hazard mitigation efforts. These problems have prevented quantitative interpretation of fumarole temperature variation. In contrast, the continuous collection and correlation of other geophysical variables has greatly aided monitoring activitics and the understanding of volcano structure and dynamics [Swanson et al., 1983; Wright and Swanson, 1987]. For example, seismic energy release has been monitored remotely and continuously and has proven to be of importance in volcano monitoring [e.g., Minikami, 1974; Malone et al., 1983]. Closely spaced electronic tiltmeters, also monitored continuously, have been of considerable utility in forecasting dome eruptions from Mount St. Helens [e.g., Chadwick et al., 1988].

In this study, temperatures in five fumaroles were monitored continuously on the summit dome of Volcán Colima, an active composite volcano in western Mexico (Figure 1), during May 1991 through May 1992. The goal of this monitoring was to collect sufficient data to help differentiate between factors controlling temperature in these furnaroles. A data logger was used to collect and telemeter these data to the Universidad de Colima observatory, located approximately $25 \mathrm{~km}$ from the volcano. Fumarole temperatures varied 


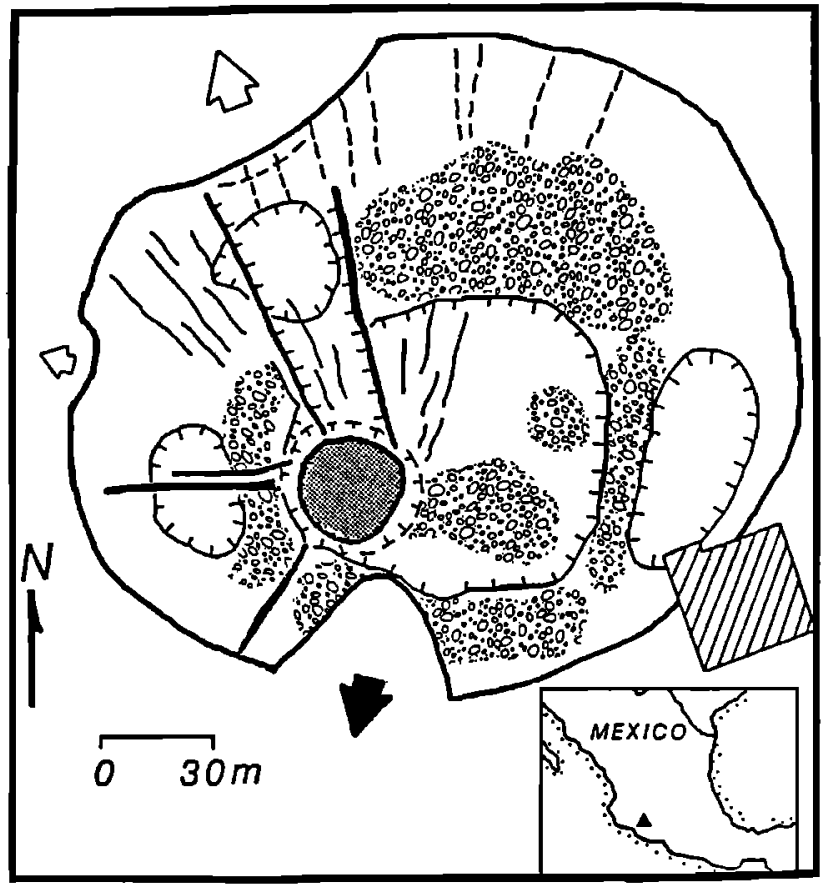

Fig. 1. Map of the summit dome of Volcan Colima prepared using field observations made on February 26 and March 2-3, 1991. A new lava dome lobe was emplaced in the south central portion of the dome (stippled area), and was surrounded by a small moat (dashed hachured lines) from which degassing was intense. Prominent fractures and faults, formed just prior to and during extrusion, are shown by solid lines, dashed where schematically shown. These new fractures often cut elevated rubbly areas on the older dome (pattern) and topographic depressions (hachured area). Rock avalanche activity has eroded the summit dome (open arrows) on the south, west, and northwest. Extrusion eventually resulted in a lava flow on the south flank (solid arrow). Fumaroles monitored between May 1991 and May 1992 are located on the southeast rim of the 1987 explosion pit (east side of the dome shown by a hachured line), and the study area (see Figure 2) is lined. Inset shows the location of Volcán Colima, Mexico.

on several timescales during the sampling period. Diumal temperature variations were particularly evident in each fumarole, possibly related to atmospheric pressure variation. Recognition of a correlation between atmospheric pressure and fumarole temperature is important because these data provide insight into the relationship between mass flow and temperature in high-temperature fumarole fields and may provide an indication of the sensitivity of fumarole temperature variations to changes in mass flow of gas and air from the volcano. A numerical model was developed to explore the dependence of fumarole temperature on mass flow and to determine whether or not mass flow variations of a reasonable magnitude can account for the observed changes in fumarole temperature.

Volcán Colima $\left(19.42^{\circ} \mathrm{N}, 103.72^{\circ} \mathrm{W}\right.$, elevation $\left.3850 \mathrm{~m}\right)$ has experienced at least 50 eruptions since 1560 [Luhr, 1981; Medina Martinez, 1983]. Since 1957 activity has been dominated by the gentle effusion of andesite lavas [Luhr and Carmichael, 1982]. This activity has filled the central crater of the volcano with a pistonlike dome.

The latest eruption episode began in March 1991, with the extrusion of lavas on the summit dome [Global Volcanism Network $(G V N), 1991 a, b$; Connor et al., 1992]. This eruption continued through July 1991, resulting in a block flow and ash flow on the south flank of the volcano and subsequent lava flow [RodgriguezElizarraras et al., 1991]. Little explosive activity accompanied this eruption, but deformation of the summil dome of the volcano was locally intense [Connor et al., 1992].
Prior to this activity, gas temperatures in the hottest fumaroles on the summit dome decreased from $895^{\circ} \mathrm{C}$ in December 1985 to $571^{\circ} \mathrm{C}$ in December 1990 [Smithsonian Scientific Event Alert Network, 1985, 1987; GVN, 1990; Connor, 1990]. This long-term decrease in fumarole temperatures ceased when fumarole activity became widespread on the dome at the outset of the March 1991 eruption. Unfortunately, fumarole temperatures were not monitored between December 1990 and March 1991. During the initial stages of this eruption, radial fractures formed on the summit dome, and fumaroles became highly concentrated along these fractures (Figure 1). Because of effusion of new dome lavas, deformation, and widespread and intense degassing, much of the summit dome, including areas previously monitored, was inaccessible during the period of this study.

\section{METHODS AND RESULTS}

\section{Automated Fumarole-Monitoring Method}

Traditionally, fumarole temperature data have been collected manually, using digital thermocouples. Given the hostility of the volcanic environment, fumaroles are generally monitored for a few minutes at a time at most, and measurements are rarely repeated at less than daily intervals. In this study an automated fumarole-monitoring system was installed on the eastern rim of the summit dome on May 13, and was made fully operational on May 16, 1991. This area is located on the 1975-1976 block lava flow near the rim of an explosion pit crater formed in 1987 (Figures 1 and 2) and about 75 $\mathrm{m}$ from the site of active lava extrusion during 1991 activity. Fumaroles are widely distributed in the area, particularly near the rim of the explosion pit. Several fracture sets, most with azimuths of approximately $070^{\circ}$ to $090^{\circ}$ (Figure 2), transect the fumarole field, and fumaroles are concentrated along these fractures. Degassing has occurred from this area since at least March 1990, but as elsewhere on the summit dome, activity was observed to increase fol-

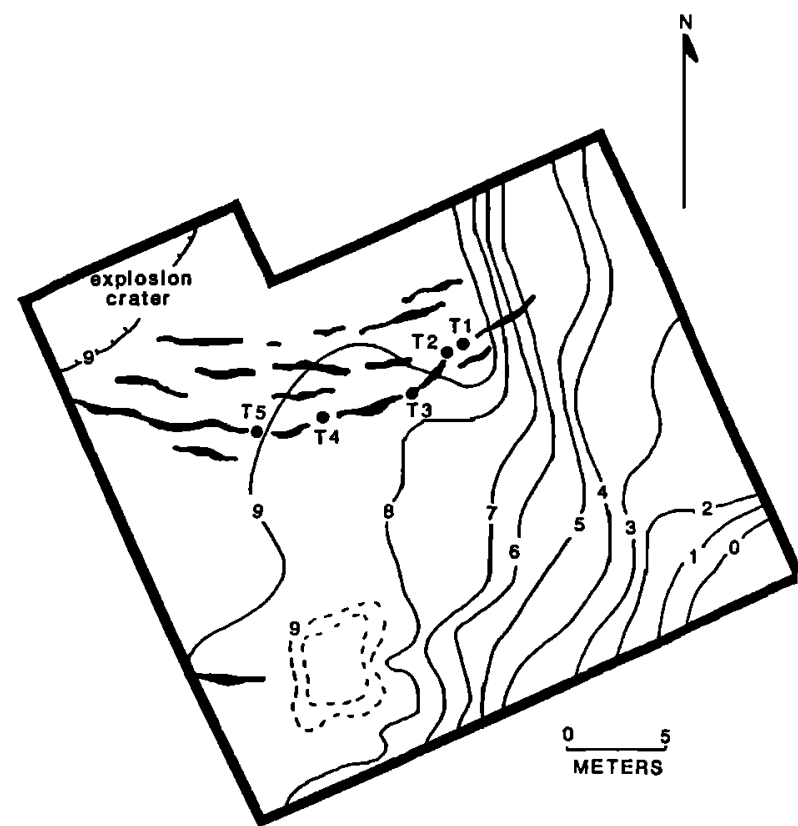

Fig. 2. Thermocouples (T1-T5) located along the most continuous fracture (Arreola fracture) within a fracture set (thick solid lines), near the southeast rim of the 1987 explosion pit (see Figure 1). The fracture is oriented $080^{\circ}$ $090^{\circ}$ and varies in width from 0.1 to $0.3 \mathrm{~m}$. The thermocouples are spaced between 2 and $5 \mathrm{~m}$ apart. The southeast rim of the explosion pit is just visible in the northwest quadrant of the map (hachured line). Elevations, relative to an arbitrary datum, were surveyed in by tape and compass. Contour interval is $1 \mathrm{~m}$ (dashed line where inferred). 
lowing renewed seismic activity and extrusion of lavas in March 1991 [GVN, 1991a]. Most fumaroles in this area have temperatures of between $200^{\circ} \mathrm{C}$ and $250^{\circ} \mathrm{C}$, but fumaroles located within fractures are much hotter, generally having temperatures between $350^{\circ} \mathrm{C}$ and $600^{\circ} \mathrm{C}$. The number of fumaroles, and fumarole temperatures, drop off quickly downslope from the crater rim. No fumaroles were found more than $50 \mathrm{~m}$ downslope from the explosion crater rim. Five fumaroles were monitored during the sampling period (thermocouples T1-T5 in Figure 2), located along a single fracture (named the Arreola fracture). Air temperature at the data logger was monitored simultaneously, and atmospheric pressure was monitored during April and May 1992.

The fumarole-monitoring system consists of a programmable Campbell Scientific data logger (model 21x), thermocouples, and peripheral equipment to power the system, radiotelemeter, and store the data. Atmospheric barometric pressure was recorded by the data logger using a Visala mountain barometer with a precision of 0.1 mbar. The data logger and peripheral equipment are widely used in meteorological and similar applications and are specifically designed for use in a wide range of atmospheric conditions. Chromel/Alumel thermocouple leads were run from the data logger to the fumaroles. Teflon-coated, shielded thermocouple wire was used in relatively cool areas $\left(<200^{\circ} \mathrm{C}\right)$ between the data logger and the fumarole field. Ceramic overbraided probes ( $3 \mathrm{~m}$ in length) were inserted into the fumaroles. Total lead length varied from approximately 20 to $30 \mathrm{~m}$. Experimentation indicates that thermocouple leads up to $100 \mathrm{~m}$ in length can be used without affecting the quality of the data. Laboratory testing with a 1-atm furnace and field comparison with a standard digital thermocouple indicate that the monitoring system is accurate to $+/-3^{\circ} \mathrm{C}$ between $200^{\circ} \mathrm{C}$ and $850^{\circ} \mathrm{C}$. Temperature and barometric pressure data were recorded digitally by the data logger and radiotelemetered periodically to the volcano observatory at the Universidad de Colima, a distance of approximately $25 \mathrm{~km}$. There the data were automatically downloaded to a floppy disk.

\section{Fumarole Temperature Measurements}

Representative data collected during 1991 and 1992 are shown in Figures 3-6. In general, there is a decrease in fumarole temperature from the crater rim to the east, and there is a high degree of correlation between temperatures in some fumaroles. Daily variation in fumarole temperature is significant and accounts for most of the observed variance in temperature. Commonly, temperatures vary by as much as $25^{\circ} \mathrm{C}$ in a single day in the hotter fumaroles and by as much as $50^{\circ} \mathrm{C}$ in the lower-temperature fumaroles. The dependence of amplitude of temperature variation on mean fumarole temperature is apparent in Figure 3. Fumaroles with low mean temperatures generally have greater daily variation than fumaroles with higher mean temperatures.

Fumarole temperature variations are well correlated with barometric pressure variation. Daily and semidiurnal variations in fumarole temperature correspond to changes in barometric pressure of as little as a few millibars (Figures $4 a$ and $4 b$ ). Longer-wavelength variation in atmospheric pressure, related to changing weather conditions, also produce long-wavelength temperature variations in some fumaroles along the Arreola fracture. For example, a lowpressure system in April 1992 correlates with an increase in fumarole temperature during the same period (Figure 5).

Long-term changes in fumarole temperature were minimal. Temperature data from two fumaroles representative of variation are given in Figure 6 . The greatest change in mean temperature along the fracture was observed in spring and summer 1991. During this time, high-temperature fumaroles cooled gradually. Low-tempera-

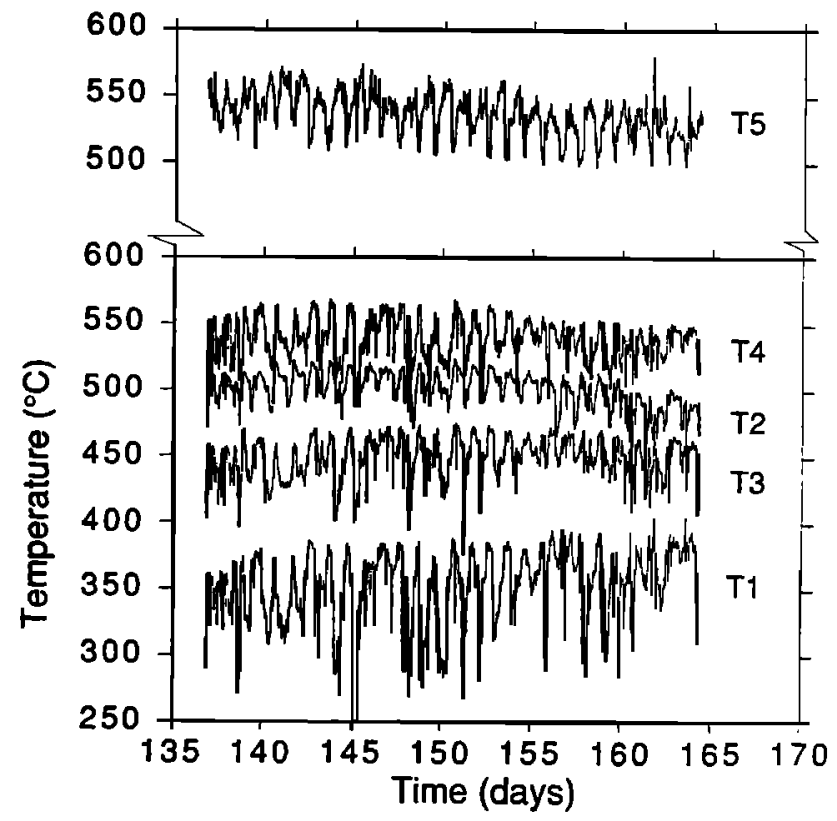

Fig. 3. Temperatures in five fumaroles (T1-T5) (see Figure 2) monitored in May and June of 1991. Sampling interval is $20 \mathrm{~min}$. The hottest fumaroles, T4 and T5, are located nearest the explosion pit; cooler fumaroles are 10cated downslope. Each fumarole has significant diumal variation; T1 has the largest diurnal variation, and $\mathrm{T} 2$ has the smallest diumal variation. Trends are also apparent in several of the fumaroles. Time is in days since January 1, 1991. (Day 135 is May 15.)

ture fumaroles heated during the same period. Subsequently, all fumaroles cooled very gradually (Figure 6). This trend would have been difficult or impossible to recognize without the continuous collection of data because daily variations are large by comparison. Although abrupt changes in mean daily temperature occurred in some fumaroles, such as in T3 around day 190 (Figure 6), this type of rapid change did not occur in other fumaroles and was not associated with any known change in volcanic activity. Overall, mean daily temperatures in individual fumaroles varied by $40^{\circ} \mathrm{C}$ to $100^{\circ} \mathrm{C}$ during the study period.

Seasonal rainfall variations near Volcán Colima are dramatic. A normal rainy season occurred between June and September 1991, and anomalous rainfall occurred in January 1992, during which period approximately $0.5 \mathrm{~m}$ of rain fell on the volcano [I. Galindo, personal communication, 1992]. Fumarole temperatures, however, were not greatly affected by rainfall during the normal rainy season,

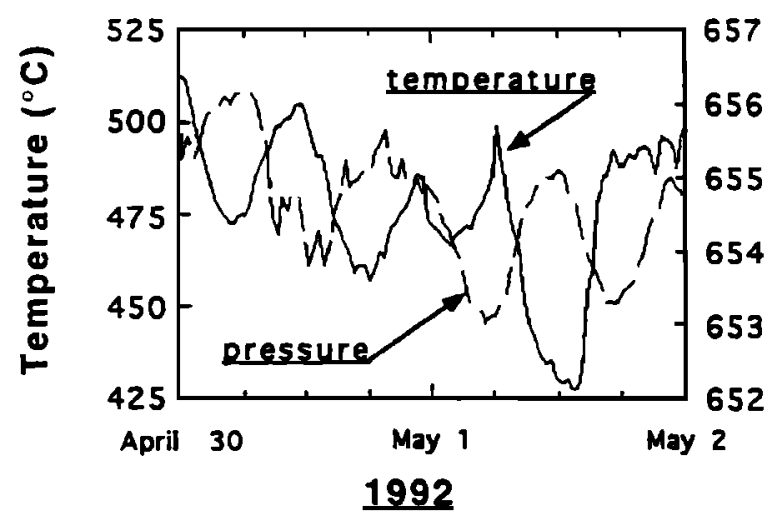

0
0
0
0
$\frac{1}{7}$
0
3
0
0
0

Fig. 4a. Temperature and pressure data collected at 20-min intervals between April 30 and May 2, 1992. The inverse correlation between temperature and pressure is fairly robust and suggests that temperature is sensitive to mass flow. 


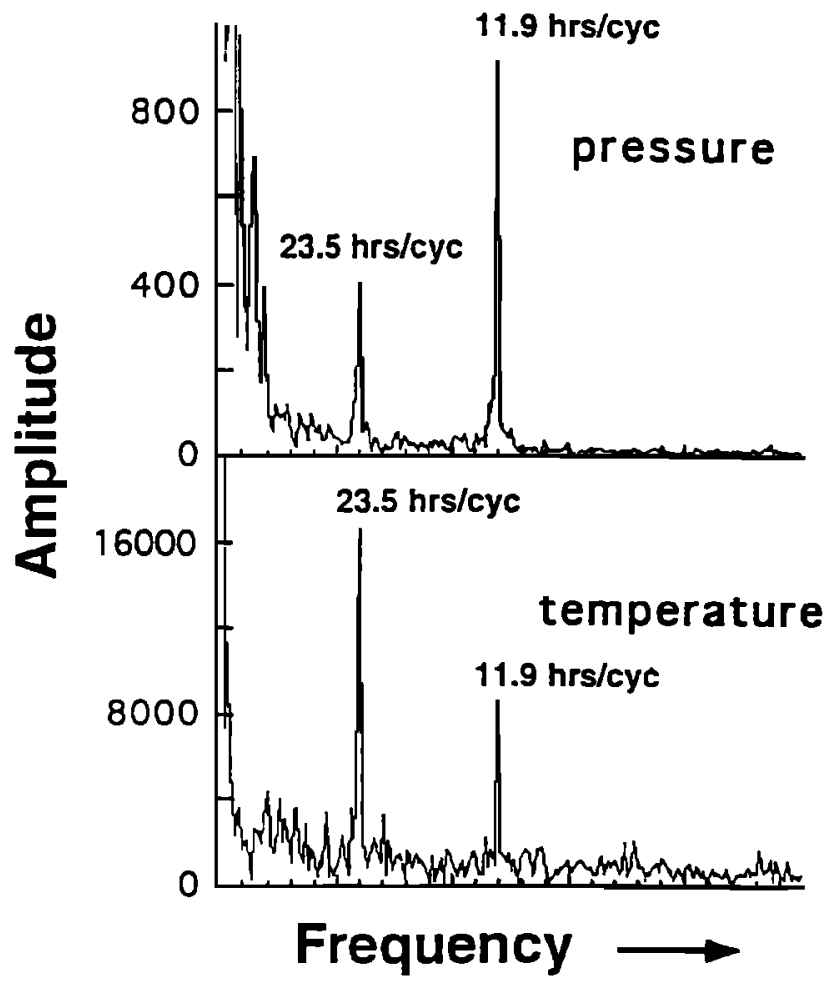

Fig. 4b. Fourier transforms of barometric pressure and fumarole temperature, indicating a high degree of correlation betwcen these data, collected at 20-min intervals between March and May 1992. Large-amplitude spectra and frequencies of 23.5 and $11.9 \mathrm{~h} /$ cycle occur. Atmospheric pressure develops this cyclicity due to tidal forcing (long-wavelength, nontidal correlation between pressure and temperature is illustrated in Figure 5).

except during actual precipitation when rain water cooled the thermocouple probes themselves. Data were not collected during two periods (Figure 6). A lightning strike disabled the instrument in late August 1991, and a battery failure occurred in late January 1992. Repairs were hampered at these times because rainfall made the volcano extremely difficult to access. Because of the failure of the system in January, it is not possible to determine if the January rains had a substantial impact on fumarole temperature. After the resumption of recording in early March 1992, temperature remained

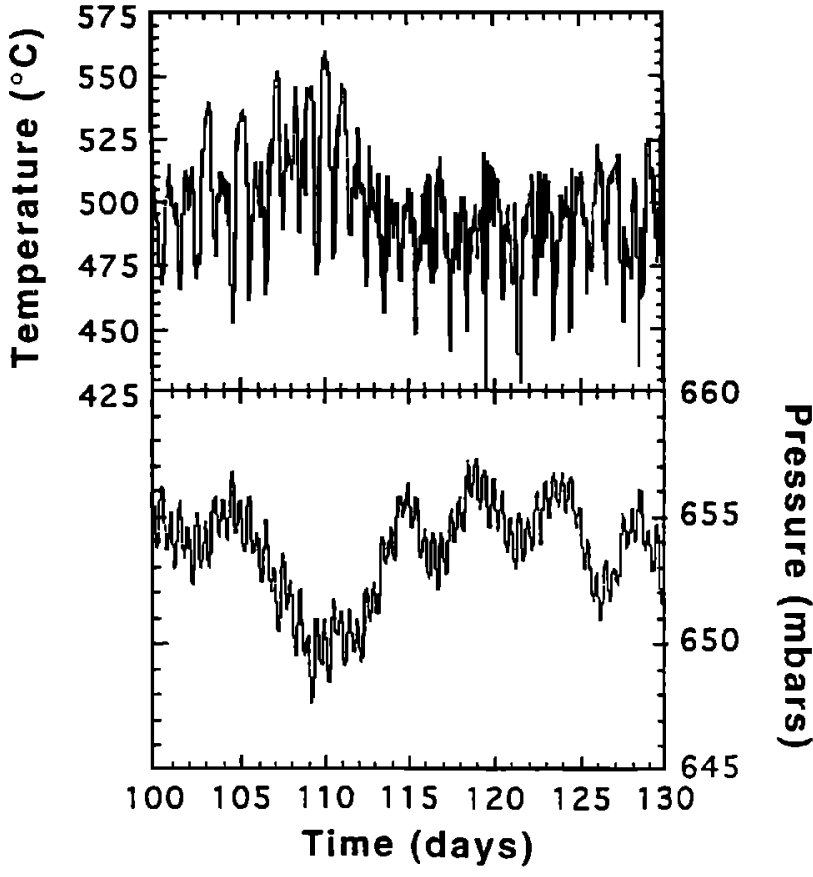

Fig. 5. Long-wavelength inverse correlation between baromatric pressure and temperature, well developed in some fumaroles. When a low-pressure tropical wave moved through the region in April 1992 (days 104-115), fumarole temperatures increased. Time is in days since January 1, 1992. (Day 100 is April 9.)

low, but this decrease is interpreted to result from gradual cooling rather than from January rainfall.

\section{STEADY STATE NUMERICAL MODEL}

\section{Method}

Analysis of fumarole temperature data suggests that significant variation in fumarole temperature occurs on relatively short timescales in response to atmospheric pressure variation. Periodic variations in geochemical variables, such as $\mathrm{CO}_{2}$ and ${ }^{222} \mathrm{Rn}$ gas flux, have been observed along fault lines [Reimer, 1980; Sato et al., $1986]$ and at some volcanoes [Tedesco et al., 1991; Baubron et al.,

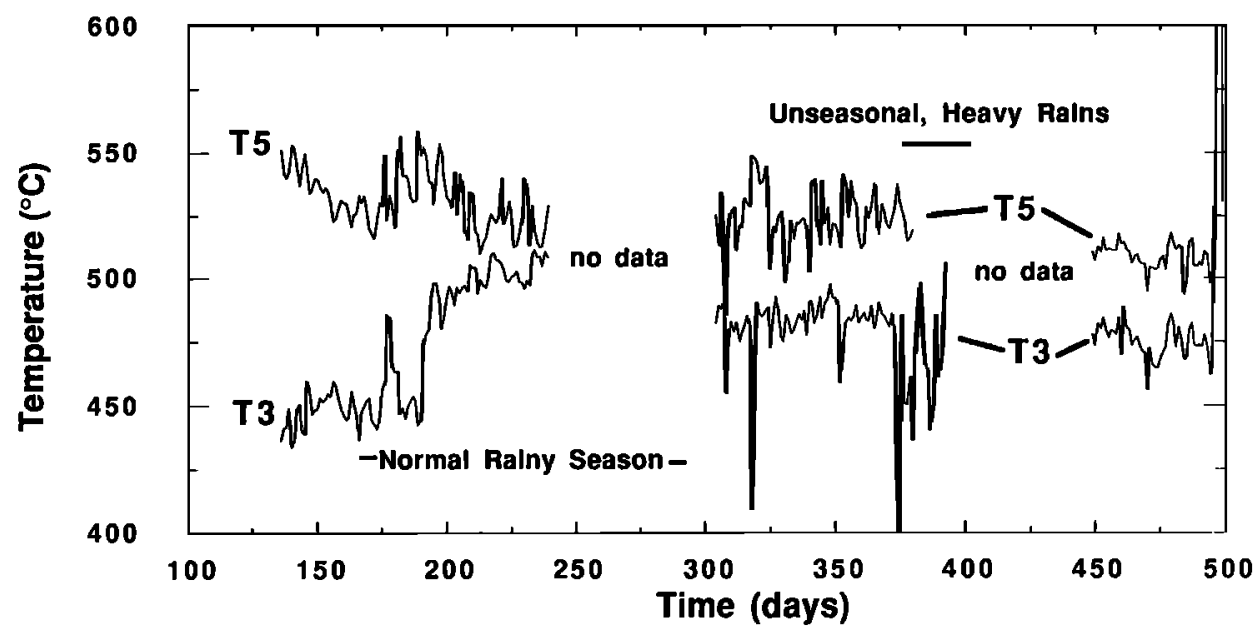

Fig. 6. Representative long-term temperature variation along the Arreola fracture, illustrated by two fumaroles (see Figure 2). These data have been averaged over 24 -hour periods. No data were collected during two periods due to instrument failure. The durations of the normal rainy season in 1991 and a period of unusually heavy rains in December 1991 and January 1992 are shown. Time is in days since January 1, 1991. 
1991]. One model for periodic change in gas flux is that variation in atmospheric pressure results in variation in mass flow of gas along a fault line, or through soil. At Volcán Colima the observed relationship between fumarole temperature and atmospheric pressure suggests that fumaroles are behaving as forced convection systems and that small changes in barometric pressure result in changes in mass flow through the fumarole conduit, which in turn results in changes in fumarole temperature. Recently, theoretical models for the dependence of fumarole temperature on various physical parameters have been described in detail [Stevenson, 1992]. Stevenson's [1992] analytical models for pipelike fumaroles and fumarole zones demonstrate that various parameters, such as mass flow, conduit geometry, and depth to magmatic heat source, can influence fumarole temperature. We have applied a simple, steady state numerical heat and mass transfer model [White, 1988] to describe heuristically the relationship between fumarole temperature and mass flow in a fracture geometry. Although the model does not reflect the inherent complexity of flow through time in fumaroles, it does account for basic patterns in temperature variation observed in the Colima data set. Transient aspects of heat and mass transfer in fumarole conduits, such as observed diurnal temperature variations, are considered qualitatively following development of this steady state model.

Fumarole temperature depends on mass flow because the gas loses heat to wall rock as it rises from depth. The amount of heat lost from the gas depends on the temperature of the wall rock, the length and geometry of the fumarole conduit, and the velocity with which gas is flowing [White, 1988; Stevenson, 1992]. In a steady state, gas will lose heat at a rate high enough to maintain a thermal boundary layer within which rock temperatures will be elevated. As a result, gas temperature decreases in a nonlinear fashion as gas rises from depth. Numerical models for temperature distribution in hot spring conduits have been discussed in detail by Sorey [1978] and Nathenson et al. [1979], and models for temperature distribution in pipelike fumaroles have been discussed by Stevenson [1992]. Boundary conditions and the theoretical basis for the numerical methods used here are amply described elsewhere [White, 1988; Minkowycz et al., 1988].

Our model is based on a fracture geometry because high-temperature fumaroles are fracture controlled at Volcán Colima. To describe the effect of mass flow variation, it is assumed that the initial gas temperature at the base of the fracture is constant. Rock surface temperature is also taken to be constant. Far from the fracture a constant geothermal gradient is maintained and, except in the fumarole itself, heat is transferred through the rock by conduction. The fracture is approximated as a parallel-sided conduit of constant width. The hydraulic diameter $D_{h}$ is used to calculate the Nusselt number and related variables.

$$
D_{h}=\frac{2 a b}{(a+b)}
$$

where $a$ is the fracture width and $b$ is fracture length (Figure 7a). For a long fracture (one with a length more than 10 times the width) it is appropriate to let $b$ equal infinity:

$$
\lim _{b \rightarrow \infty} D_{h}=2 a
$$

The fumarole gas is assumed to have the thermodynamic properties of steam. Density, thermal conductivity, viscosity, heat capacity, and the Prandlt number are varied as a function of temperature as the gas ascends the fracture [American Society of Mechanical Engineers, 1978; Kestin, 1978]. Our model does not account for variation in the thermodynamic properties of the gas that may result from compositional changes.

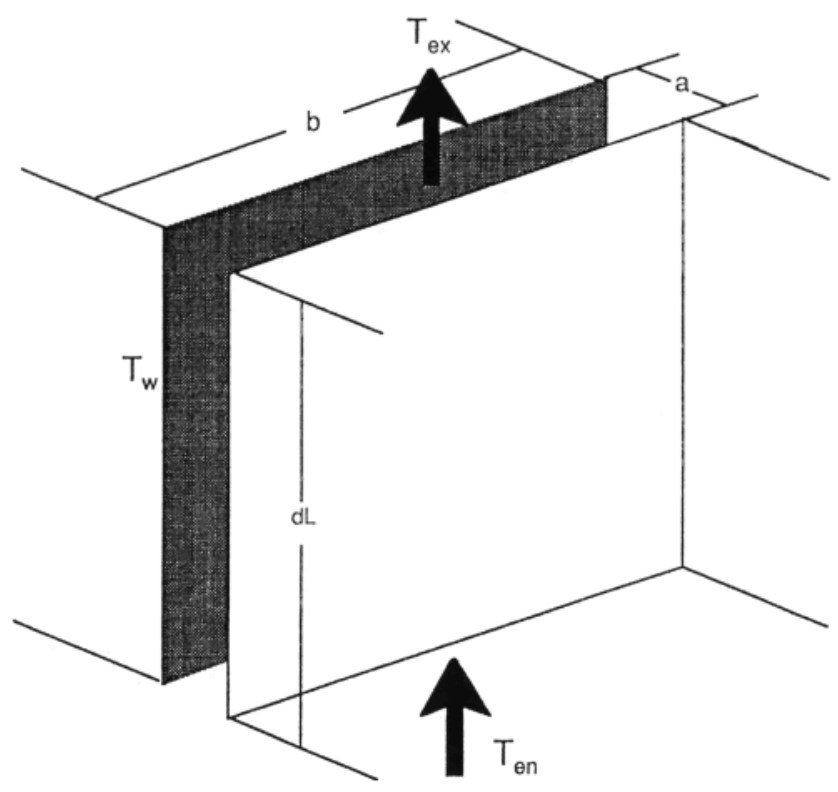

Fig. 7a. The fracture approximated by a parallel-sided conduit of length $b$ and width $a$. In the calculations used here, $b$ is much greater than $a$. For short segments of the fracture $d L$ the temperature of the gas at the base of the short segment $T_{e n}$ and wall temperature $T_{w}$ are used to calculate the exit temperature of the gas $T_{e x}$. The segment must be short enough so that $T_{w}$ can to assumed to be constant over the length of the segment. The average gas temperature within the short segment is used to calculate the thermodynamic properties of the gas.

Gas flow in the fracture will be laminar at low mass flows and is fully turbulent at high mass flows. The diameter Reynolds number $R e$ is used to determine the character of the flow

$$
\operatorname{Re}=\frac{\rho v D_{h}}{\mu}
$$

where $\rho$ and $\mu$ are the gas density and viscosity, respectively, and $v$ is the mean velocity of gas in the fracture. In the laminar flow regime the Nusselt number, $\mathrm{Nu}$, is held constant $(\mathrm{Nu}=8.66)$ [Chapman, 1984] for a long parallel-sided fracture. In the turbulent flow regime $(\operatorname{Re}>2200), \mathrm{Nu}$ is approximated using the Dittus-Boelter equation [e.g., Chapman, 1984].

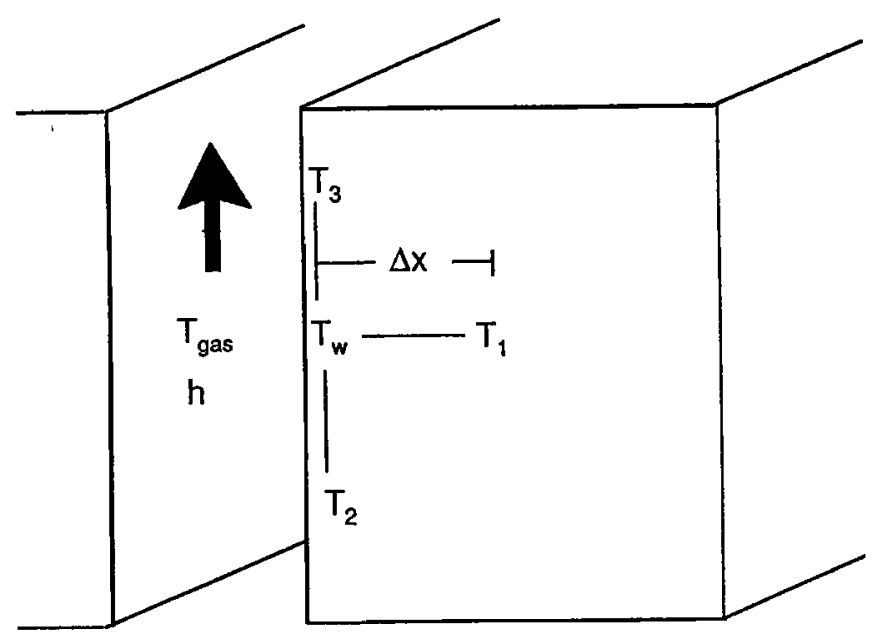

Fig. 7b. Boundary conditions at the fracture wall. The wall temperature $T_{w}$ is calculated (equation (6)) using three nodes, $T_{1}-T_{3}$, each separated from $T_{w}$ by a distance $\Delta x$, and the gas temperature and heat transfer coefficient of the gas $h$. 


$$
N u=0.027 \operatorname{Re}^{0.8} \operatorname{Pr}^{\frac{1}{3}}\left(\frac{\mu}{\mu_{w}}\right)^{0.14}
$$

where $\mu$ is the viscosity of the gas at its mean flow temperature and $\mu_{w}$ is the viscosity of the gas calculated at the wall temperature, and $P r$ is the Prandtl number. This equation applies in the fully turbulent region $(R e>4000)$. In transitional flow $(2200<R e<4000)$ the Dittus-Boelter equation does not strictly apply, and some instability in the numerical solutions results. The average heat transfer coefficient, a measure of the proporation of heat available from the gas to be conducted into the wall rock, is then given by [White, 1988]

$$
h=\frac{N u \cdot c}{D_{h}}
$$

where $c$ is the thermal conductivity of the gas, which is a function of gas temperature. The gas temperature at the exit of a short segment of fracture can be expressed in terms of the gas temperature at the entrance of the segment $T_{e n}$, the average wall temperature along the length of the short segment $T_{w}$, the mass flow rate $m$, the gas heat capacity $c p$, the heat transfer coefficient $h$, the perimeter of the cross-sectional area of the conduit $P$, and conduit segment length $d L$ (Figure 7a):

$$
T_{e x}=\left(T_{e n}-T_{w}\right) \mathrm{e}\left(\frac{-h P d L}{m c p}\right)+T_{w}
$$

For a fracture

$$
\frac{P}{m}=\frac{2(a+b)}{v \rho a b}
$$

and

$$
\lim _{b \rightarrow \infty} \frac{P}{m}=\frac{2}{v \rho a} .
$$

Equation (6) becomes

$$
T_{e x}=\left(T_{e n}-T_{w}\right) \mathrm{e}\left(\frac{-2 h d L}{v p a c p}\right)+T_{w}
$$

The average gas temperature within the conduit is

$$
T_{\mathrm{avg}}=\exp \left(\frac{\ln \left(T_{e x)}+\ln \left(T_{e n}\right)\right.}{2}\right) .
$$

A problem arises because the thermodynamic properties of the gas vary significantly as a function of temperature. Therefore an iterative solution is required to calculate the exit gas temperature $T_{e x}$. This is done by first assuming that $T_{e x}$ is the average of $T_{e n}$ and $T_{w}$, then calculating the thermodynamic properties of the gas using the average gas temperature $T_{\text {avg }}$ (equation (10)). $T_{e x}$ is then calculated using equations (3)-(9). After each calculation of $T_{e x}$ the thermodynamic properties of the gas are estimated using equation (10). The iteration proceeds until $T_{e x}$ changes by less than $0.25^{\circ} \mathrm{C}$ between successive calculations. The $T_{e x}$ of one fracture segment is used as the $T_{e n}$ of the next, higher (nearer surface) fracture segment. Fracture segments must be short enough so that the thermodynamic properties of the gas and wall temperature $T_{w}$ do not vary significantly along them. Experimentation has demonstrated that in most cases $d L=0.02 L$, where $L$ is the total depth of the fracture, is an adequate approximation. Shorter segments must be used in cases of very low mass flow or very deep fractures. Applying these procedures, the gas temperature and heat transfer coefficient are determined for the fracture, given a known wall temperature gradient. Entrance effects at the base of the conduit [White, 1988] are not considered but are not substantial for deep fractures.
Using equations (1)-(10), the gas temperature can be estimated along the conduit, provided the wall rock temperature is known. However, the wall rock temperature changes because the gas loses heat to the wall rock, and wall rock temperatures must be recalculated taking into account heat lost from the gas. In the steady state, the wall rock temperature profile is calculated by a finite difference approximation of Laplace's equation [e.g., White, 1988]. As boundary conditions, surface temperature, and the temperature at the base of the fracture are assumed to be constant and far from the fumarole, $\partial T / \partial x$ is assumed to be constant, where $x$ is distance from the fracture. The temperature on the fumarole wall is approximated by

$$
T_{w}=\frac{1}{2+B i}\left(T_{1}+\frac{\left(T_{2}+T_{3}\right)}{2}+T_{\mathrm{gas}} B i\right),
$$

where

$$
B i=\frac{h \Delta x}{k}
$$

where $k$ is the thermal conductivity of the rock, $\Delta x$ is the mesh size, $h$ is the heat transfer coefficient, $B i$ is the Biot mesh size number, $T_{\text {gas }}$ is the average gas temperature in the fracture adjacent to the wall rock where $T_{w}$ is determined, and $T_{1}, T_{2}$, and $T_{3}$ are rock temperatures along and adjacent to the fracture. The geometric relationship between $T_{w}, T_{1}, T_{2}$, and $T_{3}$ used in the finite difference model is illustrated in Figure 7b. Sorey [1978] noted that a special condition exists where the fumarole reaches the surface. High-temperature gradients exist at this point because the wall is in contact with hot gas and ambient air. Accounting for these variations is important because fumarole temperatures are measured in this location. The corner temperature $T_{c}$ is the rock temperature at the surface adjacent to the fumarole and is approximated as

$$
T_{c}=\frac{1}{1+B i}\left(\frac{\left(T_{1}+T_{2}\right)}{2}+T_{\mathrm{gas}} B i\right)
$$

where $T_{1}$ is the surface rock temperalure and is constant, and other variables are as in equation (6). Diurnal atmospheric temperature variations are not considered here, although observation indicates they have little effect on furnarole temperature $\left(<15^{\circ} \mathrm{C}\right)$.

Once the new steady state geothermal gradient is calculated, gas temperatures are recalculated using the new set of $T_{w}$ and $T_{c}$. This iterative process continues until a steady state solution is reached: gas temperatures along the conduit remain constant between successive iterations.

\section{Solutions to the Steady State Model}

Numerous solutions to the model were calculated using a variety of boundary conditions and fracture geometries. The dependence of fumarole temperature on mass flow for constant source temperature is graphed in Figure $8 a$ as a function of fracture width and in Figure $8 b$ as a function of fracture depth. Because the fumaroles along the Arreola fracture likely have a common source at some depth, Figure $8 a$ probably illustrates temperature variation as a function of mass flow within that system. The most important aspect of the numerical results is that fumarole temperature is nonlinearly dependent on mass flow. The sensitivity of temperature to mass flow is amplified in fumaroles with relatively low mass flows. This relationship persists in varying degrees for great variation in fracture width (Figure $8 a$ ), fracture depth (Figure $8 b$ ), and other boundary conditions, such as change in temperature at the source and change in the "background" geothermal gradient, far from the lumarole. Therefore the numerical solutions presented here suggest that, theoretically, similar changes in mass flow can affect fumarole temperature differently, depending on the absolute mass flow from the fumarole. By 


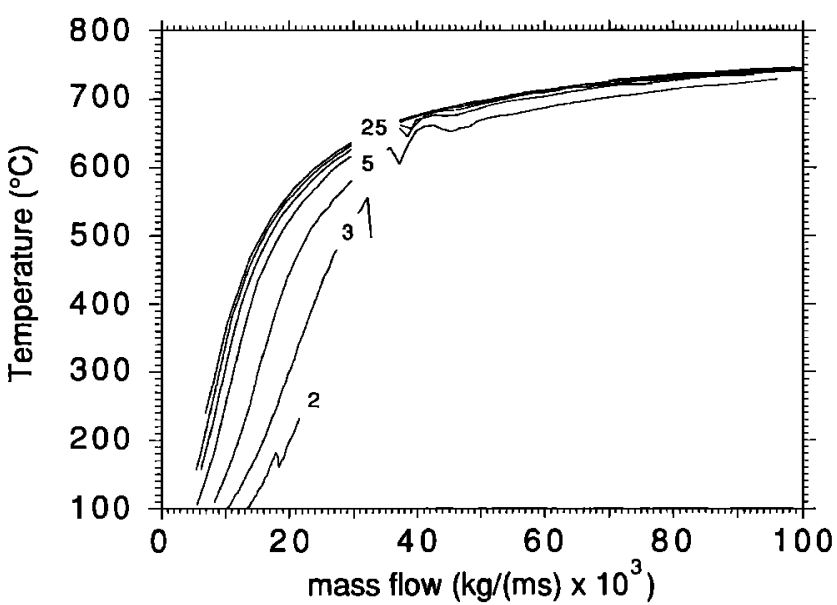

Fig. 8a. Fumarole temperature at a depth of $1 \mathrm{~m}$ below the surface, calculated for various fracture widths and mass flow (solid lines). Fracture widths are given in centimeters. For all cases illustrated, the fracture depth is 100 $\mathrm{m}$, temperatures at the base of the fumarole are taken to be $800^{\circ} \mathrm{C}$, and far from the fumarole temperatures are taken to vary from $0^{\circ} \mathrm{C}$ at the surface to $200^{\circ} \mathrm{C}$ at a depth of $100 \mathrm{~m}$. Other boundary conditions are discussed in the text. The numerical approximation becomes unstable near the transition from laminar to turbulent flow, notching each of the curves. High mass flows were not calculated for thin fractures $(<0.05 \mathrm{~m})$ because these would require very high gas velocities. The nonlinear dependence of temperature on mass flow persists for a range of fracture widths.

contrast, temperature is not as strongly dependent on geometric parameters, such as fracture width or depth to the magmatic heat source.

Comparing the model results and observed daily variation in fumarole temperature (Figure 3 ) indicates that differences in mass flow can readily account for much of the temperature variation along the Arreola fracture. Although closely spaced along the same fracture, fumaroles $T 1, T 2$, and $T 3$ have significantly different mean temperatures (Figures 2 and 3). Of these, T1 has the lowest mean temperature and the greatest daily fluctuation in temperature. $\mathrm{T} 2$ is the hottest of the three and has the smallest daily fluctuation. The model results indicate that the same change in mass flow in all three fumaroles will produce the greatest temperature change in the

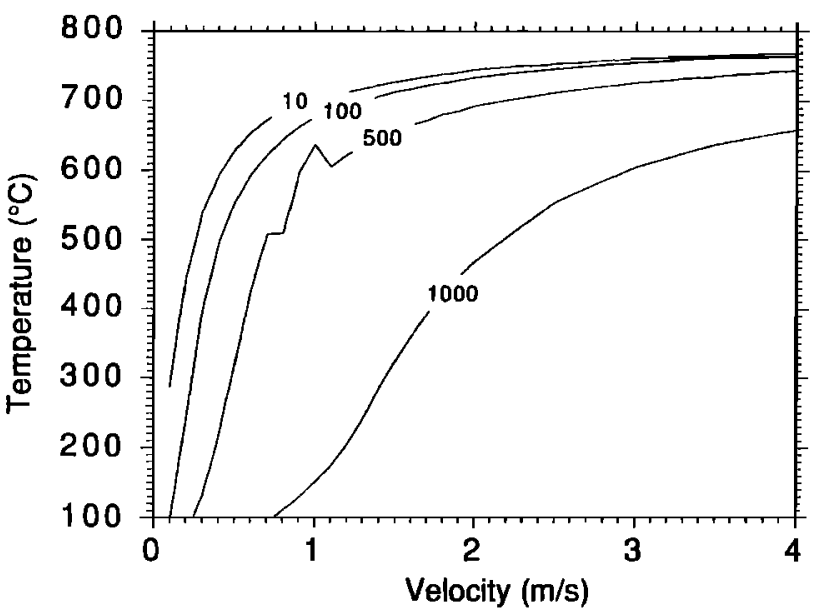

Fig. 8b. Fumarole temperature $1 \mathrm{~m}$ below the surface calculated for various fracture depths and gas velocities. In all cases the fracture width is $0.15 \mathrm{~m}$, and the local geothermal gradient is assumed to reach $200^{\circ} \mathrm{C}$ at a depth equal to the total depth of the fracture (this and other boundary conditions as in Figure $8 a$ ). Fracture lengths are reported in meters. The nonlinear dependence of temperature on mass flow persists for a range of fracture depths. coolest of the three. Although mass flow must be higher at $\mathrm{T} 2$ than at the other two fumaroles, the magnitude of daily fluctuation in mass flow in the three fumaroles may be similar. The model suggests that mass flow may be greater in T4 and T5 than in fumaroles further downslope and that these fumaroles may have larger daily fluctuations in mass flow than the other fumaroles. Alternatively, mixing of hot gas with cooler gas or meteoric vapor may vary along the length of the fracture, cooling fumaroles T1-T3 with respect to fumaroles located further upslope (T4 and T5). Differences in mixing of magmatic gases with meleoric vapor may account for the differences in behavior of hotter fumaroles (T4 and T5) and cooler fumaroles (T1-T3), but mixing is not necessary to produce the observed daily change in individual fumaroles or systematic changes between fumaroles (i.e., between fumaroles T1, T2, and T3). Geometric factors, such as fracture depth and width, play a secondary role.

The numerical model developed here does not effectively quantify the response of fumarole temperature to rapid changes in mass flow. The thermal diffusivity of rock, $\kappa$, is slow, of the order of $1 \times$ $10^{-6} \mathrm{~m}^{2} \mathrm{~s}^{-1}$ [Turcotte and Schubert, 1982], so it takes time for the system to reach a steady state. The thickness of the thermal boundary layer about the fracture can be defined as the distance from the fracture at which $\left(T-T_{0}\right) /\left(T_{w}-T_{0}\right)=0.1$, where $T$ is rock temperature at the outer limit of the thermal boundary layer, $T_{0}$ is the initial wall temperature, and $T_{w}$ is the wall temperature in the steady state. If, for example , a fracture is $25 \mathrm{~m}$ deep and $0.15 \mathrm{~m}$ wide and has a mass flow of about $0.01 \mathrm{~kg} \mathrm{~s}^{-1} \mathrm{~m}^{-1}$, the thickness of the thermal boundary layer is approximately $6.5 \mathrm{~m}$ at a depth of $12.5 \mathrm{~m}$. The time required for the temperature profile to change from a uniform geothermal gradient to one with a steady state thermal boundary layer is given by

$$
x=2 \operatorname{erfc}^{-1}(0.1) \sqrt{\kappa t}
$$

where $x$ is the thickness of the thermal boundary layer. It takes about 90 days for the rock temperature to reach a steady state. An increase in mass flow from 0.01 to $0.0125 \mathrm{~kg} \mathrm{~m}^{-1} \mathrm{~s}^{-1}$ increases the thickness of the thermal boundary layer to $7.1 \mathrm{~m}$. It will take an additional 17 days for the system to reach equilibrium. Daily variation, however, is much too rapid for the system to reach equilibrium. For example, rearranging equation (13), in 1 hour the rock temperature increases by $10 \%$ at a distance of only $14 \mathrm{~cm}$ from the fracture wall. Due to the low thermal diffusivity of rocks, rock very close to the fracture will heat in response to an increase in gas temperature much faster than this heat can be conducted away. The converse is also true; in response to a decrease in gas temperature, rock near the fracture will cool faster than heat can be conducted into the region from the surrounding rock. This has the net effect of making fumarole temperatures more sensitive to rapid, transient changes in mass flow than implied by the steady state model because the volume of rock heated, or cooled, is much smaller. Rapid changes in mass flow will induce larger changes in fumarole temperature than predicted by the steady state model. Nonetheless, because the heat transfer coefficient does not depend on the conductivity of the wall rock (equation (5)), the response of fumarole temperature is accurately portrayed in a relative way for various fracture geometries and mass flow conditions (Figures $8 a$ and $8 b)$.

\section{Discussion}

Continuous recording has revealed substantial daily variation in fumarole temperature in fractures near the SE rim of the 1987 explosion crater. Similar variations have been identified in shorter data sets collected in different, now inaccessible, fumarole areas of the summit dome using the sampling techniques similar to those described here [Connor, 1990; GVN, 1990]. Daily variations in fu- 
marole temperature of this magnitude have not been identified at Volcán Colima, or other volcanoes, when traditional sampling methods are employed. The daily change in fumarole temperature along the Arreola fracture is large and illustrates the inadequacy of traditional methods, involving nonautomated systems. Fumarole temperatures must be sampled with a high frequency ( $\leq 1$ hour), and several fumaroles must be monitored simultaneously in order to fully characterize temperature variation. Traditional sampling methods would probably miss subtle trends in temperature because daily variation introduces a significant aliasing problem. Even if a fumarole were sampled at the same time daily, an extremely difficult task at Volcán Colima, the limited number of data points collected in 1 month would render statistical and time series analysis useless. In comparison, automatic sampling provides the resolution required to reveal these trends quickly and with comparatively little effort. Although dramatic variation in fumarole temperatures, such as those preceding volcanic activity [e.g., Barquero, 1983], have been identified using handheld digital thermometers, additional details about the timing and character of these rapid changes may be revealed through automated, multichannel collection of temperature data.

Long-term variation in temperatures in the Arreola fracture were slight $\left(\leq 100^{\circ} \mathrm{C}\right)$ during the sampling period. There is, however, a broad correlation between volcanic activity and fumarole temperatures. Effusive activity on the dome occurred between March and May 1991 and continued at a much lower rate through June [Rodgriguez-Elizarraras et al., 1991]. Following this period, no eruptive activity occurred on the dome. During the waning stages of and immediately following effusive activity, between May and August 1991, fumaroles along the Arreola fracture were not in equilibrium, and heating or cooling trends were inconsistent along the length of the fracture. For example, abrupt changes in temperature occurred in some fumaroles during this period, such as a $70^{\circ} \mathrm{C}$ increase in mean temperature in T3 during a 3.5-day period near day 190 (Figure 6), that were not observed in other fumaroles. These changes in temperature indicate that rapid changes in mass flow or mixing were occurring along the length of fracture. Gradual cooling was observed in all fumaroles between November 1991 and May 1992. This gradual cooling may have been in response to a decrease in mean mass flow, a cooling of the magmatic source region, or both and is consistent with the waning of magmatic activity. Variance in mean daily temperatures was much reduced by May 1992, and patterns in mean temperature variation were more consistent between fumaroles, suggesting that flow along the fracture was more nearly equilibrated at that time.

\section{Diurnal Variation and Mass Flow}

All of the fumaroles have a statistically significant diurnal temperature variation. Periodic variation in geothermal phenomena has been known for a long time. For instance, geysers and hot springs owe their periodic activity to the complexities of conduit geometry, recharge rates, and, to a lesser extent, external forcing [Rhinehart, 1976; Sorey and Lewis, 1976]. Fortnightly periodicity in volcano degassing has been attributed to the Earth tide [Connor et al., 1988], and longer-term variation in fumarole temperature has been attributed to seasonal effects [Stoiber et al., 1975]. The latter two examples indicate that external forcing is of some consequence in actively degassing volcanoes. Recently, continuous monitoring of $\mathrm{CO}_{2}$, $\mathrm{He}$, and $\mathrm{Rn}$ gases for brief periods at Mount Etna and Vulcano, Italy, has revealed similar diurnal variation in gas flux [Allard et al., 1990; Baubron et al., 1991; Tedesco et al., 1991]. Diurnal variation has long been identified in gas flux along active faults [e.g., Reimer, 1980; Talwani et al., 1980; Teng and Sun, 1986; Sato et al., 1986]. Reimer [1980] correlated gas flux from soils with nu- merous atmospheric variables, including air and soil temperature, wind velocity, and, to a lesser extent, barometric pressure. McCarthy and Reimer [1986] suggested that atmospheric pumping causes changes in gas flux along fault lines and that gas flux best correlates with rate of change in atmospheric pressure. Sato et al. [1986] noted that natural variation in $\mathrm{H}_{2}$ flux along the Calaveras fault, California, is diurnal, but phase changes occur from site to site. The nearly continuous diurnal variation in fumarole temperature in five fumaroles and the inverse correlation between temperature and atmospheric pressure indicate that small changes in pressure result in changes in mass flow through the conduit. Stevenson [1992] has pointed out that nearly all gas expansion should take place immediately above the magma and that very little expansion of gas will take place in the fumarole conduit as the gas rises. This theoretical result is supported by observations at Colima. A pressure change of a few millibars at the surface can only substantially effect flow if the total change in pressure along the length of the conduit is small. This makes sense in a high-temperature, low-viscosity, low-mass-flow, forced convection system.

The numerical model developed here does not account for several factors which, at least in some circumstances, likely affect temperature. Convection of fluids in the surrounding rock [e.g., Sorey, 1978] and nearby fumaroles [Stevenson, 1992] likely affects the local geothermal gradient considerably, with a corresponding effect on fumarole temperature. This factor has only been considered indirectly, by altering the local geothermal gradient. Mixing with shallowly circulating meteoric vapor and air has not been considered either. However, the lack of seasonal variation in temperature, or substantial change during periods of unusually high rainfall (Figure 6), indicate that direct near-surface mixing has little impact on temperature in these fumaroles. Either the meteoric component in the gas is small, or, more likely, the meteoric component is deeply circulating and, as a result, is unaffected by seasonal changes in rainfall or air temperature. Other factors, including fracture roughness and interconnectedness, have not been considered even though they likely influence the properties of flow in fumaroles. Clearly, without accounting for these factors, the model does not absolutely quantify the behavior of the system; it merely illustrates the dependence of fumarole temperature on mass flow. The fact that factors such as fracture roughness remained constant during the sampling period, but fumarole temperatures varied significantly, supports the conclusion that mass flow exerts a strong influence on fumarole temperature.

\section{Fumarole Temperature Monitoring}

Certainly, the sampling methods introduced here alleviate many of the problems associated with the interpretation of fumarole temperature measurements. In practice, the method provides a direct measure of thermal activity on Volcán Colima, while minimizing the hazards associated with the collection of such data. Whether multichannel, rapid sampling of fumarole temperatures can overcome the localized nature of the method in practice is not yet clear. However, two points should be noted. First, the timescales of variation introduced by local and atmospheric factors should be quite different from those associated with magma movement or related changes in the thermal structure of the volcano. For example, automated collection of data makes it relatively easy to identify the effects of atmospheric forcing. As the timescales of these variations become better understood, variations associated with magma degassing should become more readily apparent. Second, observations of temperature variation along the Arreola fracture, coupled with numerical experimentation, provide evidence of the fundamental, nonlinear relationship between fumarole temperature and mass flow. Mass flow, or gas velocity, in fumaroles is difficult to 
measure directly and has never been done successfully on a continuing basis, largely due to the high temperatures and corrosive nature of the gases. Although thermocouples provide an indirect measure of mass flow, they are, in comparison, inexpensive and incredibly resilient. Direct mass flow measurements made periodically, such as those made at low-temperature fumaroles in Long Valley [Sorey et al., 1993], may prove to be an excellent method for better quantifying the relationship between mass flow and temperature, provided adequate measurements can be made at high temperatures and low mass flows.

Temperature measurements, made continuously, may be useful for the detection of mass flow changes prior to explosive volcanic eruptions. Considerable energy has been devoted to the measurement of mass flow from volcanoes, using correlation spectroscopy [Stoiber et al., 1983] and similar approaches [Sato and McGee, 1982; Hirabayashi et al., 1986]. In many instances significant changes in gas flux occur prior to explosive eruptions [e.g., Malinconico, 1979; Stoiber et al., 1980]. Absolute changes in the gas flux of certain gas species, such as $\mathrm{SO}_{2}$ and $\mathrm{Rn}$, are known to correlate well with long-term changes in activity and noneruptive events [Greenland et al., 1985; Stoiber et al., 1986; Connor et al., 1988]. Automated fumarole temperature monitoring may provide a reliable means of assessing mass flow from fumaroles on a nearly continuous basis. At Volcán Colima this approach has revealed details in temperature variation not previously evident. In light of these results, it is clear that the utility of fumarole temperature measurements in the monitoring of active volcanoes has yet to be fully explored.

\section{CONCLUSIONS}

1. Collection of fumarole temperature data using a programmable data logger, and telemetry of these data, provides an effective means of monitoring temperature variation in much greater detail than is possible using traditional methods. As a result, subtle changes and rapid fluctuations in temperature are easily identified.

2. Fumarole temperatures are nonlinearly dependent on mass flow. Geometric factors, such as fracture width, play a secondary role. For a given fumarole, changes in mass flow alone can produce substantial changes in temperature. Observed temperature changes at Volcán Colima are best accounted for by changes in mass flow.

3. At Volcán Colima fumarole temperatures vary in response to small changes in atmospheric pressure. The nature of this variation is enhanced in low-temperature fumaroles. Changes in degassing occurred from fumaroles along the Arreola fracture between May 1991 and May 1992. During and immediately following effusive activity, changes in degassing were abrupt and inconsistent along the length of the fracture. Following this period, temperatures decreased gradually, and there was a higher degree of correlation between fumaroles, indicating that degassing was more uniform along the length of the fracture.

Acknowledgments. Numerous individuals and organizations assisted in the installation of the fumarole-monitoring network on Volcán Colima. In particular, we thank Carlos Navarro, Laura Connor, Mitchell Ventura, Gilberto Ornales, Jill Garfield, Cameron and Topeka Ellis, John Magsino, and EarthWatch volunteers for their assistance in carrying equipment, debugging the network, and working cheerfully and diligently under nasty conditions. Helpful discussions with Grenville Draper, Ignacio Galindo, and Jorge Piza are gratefully acknowledged. The Centro Internacional de Cientificas Basicas, the Mexican Military (Militaria Zona 20/a), Proteccion Civil, and the Universidad de Colima provided logistic and technical support without which this project could not have succeeded. This manuscript was reviewed by Michael Sorey and Robert Symonds. Their comments are appreciated. This work was supported by grants from the National Science Foundation (EAR-9017845) and EarthWatch.

\section{REFERENCES}

Abiko, T., Temporal variation in chemical compositions of hot-springs Toyako- and Sohbetsu-Onsen after the 1977 to 1978 eruption of Usu volcano, in Fundamental Research for Predicting Volcanic Eruptions Through Observation of Volcanic Gases, edited by J. Ossaka, Spec. Rep. Grant-in-Aid Nat. Disaster Sci. A-59-4, p. 141, National Research Instjtute for Earth Science and Disaster Prevention, Tsukuba, Japan, 1984.

Abiko, T., Hot spring temperatures at Usu volcano, Japan, in Historical Unrest at Large Calderas of the World, vol. 2, ediled by C.G. Newhall and D. Dzurisin, U.S. Geol. Surv. Bull., 1855, 559-560, 1988.

Allard, P., J. Carbonnelle, D. Dajlevic, J. Le Bronec, P. Morel, M.-C. Robe, R. Faivre-Pierret, J.-C. Sabroux, and P. Zettwood, Eruptive and diffuse emissions of carbon dioxide from Etna volcano, Sicily, Nature, 344, 51$53,1990$.

Allen, E.T., and E.G. Zies, A chemical study of fumaroles of the Katmai region, Tech. Pap. Natl. Geogr. Soc., 2, 75-155, 1923.

American Society of Mechanical Engineers, ASME Steam Tables, 3rd ed., 78 pp., New York, 1978.

Barquero, J., Termometria de la fumarola del Volcán Poás, Bol. Volcano, 13, $11-12,1983$.

Barquero, J., Changes in fumarole temperatures at Volcán Poás, in Historical Unrest at Large Calderas of the World, vol. 2, edited by C.G. Newhall and D. Dzurisin, U.S. Geol. Surv. Bull., 1855, 878-879, 1988.

Baubron, J.-C., P. Allard, J.-C. Sabroux, D. Tedesco, and J.-P. Toutain, Soil gas emanations as precursory indicators of volcanic eruptions, J. Geol. Soc. London, 148, 571-576, 1991.

Chadwick, W.W., R.J. Archuleta, and D.A. Swanson, The mechanics of ground deformation precursory to dome-building extrusions at Mount St. Helens 1981-1982, J. Geophys. Res., 93, 4351-4366, 1988.

Chapman, A.J., Heat Transfer, 4th ed., 607 pp, Macmillan, New York, 1984.

Connor, C.B., Continuous monitoring of fumarole temperatures, Colima volcano, Mexico (abstract), Eos Trans. AGU, 71, 1694, 1990.

Connor, C.B., R.E. Stoiber, and L.L. Malinconico, Jr., Variation in sulfur dioxide emissions related to Earth tides, Halemaumau Crater, Kilauea volcano, Hawaii, J. Geophys. Res., 93, 14,867-14,871, 1988.

Connor, C.B., S.B. Lane, and B.M. Clement, Structure and thermal characteristics of the summit dome, March 1990-March 1991: Volcán Colima, Mexico, paper presented at Tercera Reunión Nacional y Segunda Reunión Internacional de Vulcanología, Volcán Colima, Resúmenes, Universidad de Colima, Colima, Jan. 18-22, 1992.

Global Volcanism Network (GVN), Activity at Colima, Mexico, Bull. Global Volcanism Network Smithson. Inst., 15(12), 2-4, 1990.

Global Volcanism Network (GVN), Activity at Colima, Mexico, Bull. Global Volcanism Network Smithson. Inst., 16(4), 7-8, 1991 a.

Global Volcanism Network (GVN), Activity at Colima, Mexico, Bull. Global Volcanism Network Smithson. Inst., 16(2), 2-3, 1991 b.

Greenland, L.P., W.I. Rose, and J.B. Stokes, An estimate of gas emissions and magmatic gas content from Kilauea volcano, Geochim. Cosmochim. Acta, 49, 125-129, 1985.

Hirabayashi, J., J. Ossaka, and T. Ozawa, Geochemical study of volcanic gases al Sakurajima volcano, Japan, J. Geophys. Res., 91, 12,167-12,176, 1986.

Keith, T.E.C., Fossil and active fumaroles in the 1912 eruptive deposits, Valley of Ten Thousand Smokes, Alaska, J. Volcanol. Geotherm. Res., 45, 227-254, 1991.

Kestin, J., Thermal conductivity of water and steam, Mech. Eng., 47, 1978.

Luhr, J.F., Colima: History and cyclicity of enuptions, Volcano News, 7, 1-3, 1981.

Luhr, J.F., and I.S.E. Carmichael, The Colima volcanic complex, I, Post-caldera andesites from Volcán Colima, Contrib. Mineral. Petrol., 71, 343372, 1982.

Malinconico, L.L., Fluctuations in $\mathrm{SO}_{2}$ emissions during recent eruptions of Mt. Etna, Nature, 278, 43-45, 1979.

Malone, S.D., C. Boyko, and C.S. Weaver, Seismic precursors to the Mount St. Helens eruptions in 1981 and 1982, Science, 221, 1376-1378, 1983.

McCarthy, H.J., and G.M. Reimer, Advances in soil gas geochemical exploration for natural resources: Some current examples and practices, $J$. Geophys. Res., 91, 12,327-12,338, 1986.

McClelland, L., T. Simkin, M. Summers, E. Nielsen, and T.C. Stein, Global Volcanism, 1975-1985, 655 pp, Prentice-Hall, Englewood Cliffs, N. J. 1989.

Medina Martinez, F., Analysis of the eruptive history of Volcán de Colima, Mexico (1560-1980), Geofis. Int., 22, 157-158, 1983.

Minikami, T., Prediction of volcanic eruptions, in Developments in Solid Earth Geophysics (Physical Volcanology), vol. 6, edited by L. Civetta, pp. 313-333, Elsevier, Amsterdam, 1974. 
Minkowycz, W.J., E.M. Sparrow, G.E. Schneider, and R.H. Pletcher, Handbook of Numerical Heat Transfer, 1024 pp, John Wiley, New York, 1988.

Nathenson, M., T.C. Urban, and W.H. Diment, Approximate solution for the temperature distribution caused by flow up a fault and its application to temperatures measured in a drillhole at Raft River geothermal area, Cassia County, Idaho, Geothermal Resources Council, Transactions, $3: 477$ $480,1979$.

Reimer, G.M., Use of soil-gas helium concentrations for earthquake prediction: Limitations imposed by diumal variation, J. Geophys. Res., 85, 3107-3114, 1980.

Rhinehart, J.S., Influence of tidal strain on geophysical phenomena, In paper presented at Seventh Symposium on Earth Tides, International Union of Geological Sciences, Stutıgart, 1976.

Rodgriguez-Elizarraras, S., C. Siebe, J.C. Koromorowski, J.M. Espindola, and R. Saucedo, Field observations of the pristine block- and ash-flow deposits emplaced April 16-17, 1991, at Volcán Colima, Mexico, J. Volcanol. Geotherm. Res., 48, 399-412, 1991.

Sato, M., and K.A. McGee, Continuous monitoring of hydrogen on the south flank of Mt. St. Helens, in The 1980 Eruptions of Mount St. Helens, Washington, edited by P.W. Lippman and D.R. Mullineaux, U.S. Geol. Surv. Prof. Pap., 1250, 209-220, 1982.

Sato, M., A.J. Sutton, K.A. McGee, and S. Russell-Robinson, Monitoring of hydrogen along the San Andreas and Calaveras faults in central California in 1980-1984, J. Geophys. Res., 91, 12,315-12,326, 1986.

Smithsonian Scientific Event Alert Network, Colima volcano, SW Mexico, Smithson. Sci. Event Alert Network Bull., 10(11), 9-10, 1985.

Smithsonian Scientific Event Alert Network, Colima volcano, SW Mexico, Smithson. Sci. Event Alert Network Bull., 12(2), 11, 1987.

Sorey, M.L., Numerical modeling of liquid geothermal systems, U.S. Geol. Surv. Prof. Pap., 1044-D, 25 pp., 1978.

Sorey, M.L., and R.E. Lewis, Convective heat flow from hot springs in the Long Valley caldera, Mono County, California, J. Geophys. Res., 81, 810$820,1976$.

Sorey, M.L., B.M. Kennedy, W.C. Evans, C.D. Farrar, and G.A. Suemnicht, Helium-isotope and gas discharge variations associated with crustal unrest in Long Valley caldera, California, 1989-1992, J. Geophys. Res., 98, 15,871-15,889, 1993.

Stevenson, D.S., Heat transfer in active volcanoes: Models for crater lake systems, Ph.D. thesis, Open Univ., Cambridge, England, 235 pp., 1992.

Stoiber, R.E., W.I. Rose, I.M. Lange, and R.W. Birnie, The cooling of Izalco volcano (E1 Salvador) 1964-1974, 1975, Geol. Jahrb., 13, 193-205, 1975.
Stoiber, R.E., S.N. Williams, and L.L. Malinconico, Mount St. Helens, Washington, 1980 volcanic eruption: Magmatic gas component during the first 16 days, Science, 208, 1258-1259, 1980.

Stoiber, R.E., L.L. Malinconico, and S.N. Williams, Use of the correlation spectrometer at volcanoes, in Forecasting Volcanic Events, edited by $\mathrm{H}$ Tazieff and J.-C. Sabroux, pp. 425-444, Elsevier, New York, 1983.

Stoiber, R.E., S.N. Williams, and B. Hubert, Sulfur and halogen gases at Masaya caldera complex, Nicaragua: Total flux and variation with time J. Geophys. Res., 91, 12,215-12,231, 1986.

Swanson, D.A., T.J. Casadevall, D. Dzurisin, S.D. Malone, C.G. Newhall, and C.S. Weaver, Predicting eruptions at Mount St. Helens, June 1980 through December, 1982, Science, 221, 1369-1376, 1983.

Talwani, P., W.S. Moore, and J. Chiang, Radon anomalies and microearthquakes at Lake Jocassee, South Carolina, J. Geophys. Res., 85, 3079-3088, 1980.

Tedesco, D., J.P. Toutain, P. Allard, and R. Losno, Chemical variations in fumarolic gases at Vulcano Island (southern Italy): Seasonal and volcanic effects, J. Volcanol. Geotherm. Res., 45, 325-334, 1991.

Teng, T., and L.F. Sun, Research on groundwater radon as a fluid phase precursor to earthquakes, J. Geophys. Res., 91, 12,305-12,313, 1986.

Turcotte, D.L., and G. Schubert, Geodynamics: Application of Continuum Physics to Geologic Problems, 542 pp., John Wiley, New York, 1982.

White, F.M., Heat and Mass Transfer, 718 pp., Addison-Wesley, Reading, Mass., 1988.

Wright, T.L., and D.A. Swanson, The significance of observations at active volcanoes, paper presented at Hawaiian Symposium on How Volcanoes Work, Hawaii. Volcano Obs., Hilo, Jan. 19-25, 1987.

Zettwood, $\mathbf{P}$., and $\mathbf{H}$. Tazieff, Instrumentation for measuring and recording mass and energy transfer from volcanoes to the atmosphere, Bull. Volcanol., 36, 1-19, 1973.

B.M. Clement, S.B. Lane, X. Song, and J. West-Thomas, Department of Geology, Florida International University, Miami, FL 33199.

C.B. Connor, Center for Nuclear Waste Regulatory Analyses, Southwest Research Institute, 6220 Culebra Road, San Antonio, TX 78238-5166.

(Received March 8, 1993;

revised July 22,1993 ;

accepted July 30, 1993.) 